\title{
AN EMPIRICAL STUDY INTO THE USE OF A PROJECT MANAGEMENT OFFICE IN IT PROJECTS IN SAUDI ARABIA
}

\author{
Umar A. Altahtooh, University of Manchester, umar.altahtooh@postgrad.manchester.ac.uk \\ MargaretW. Emsley, University of Manchester, margaret.emsley@manchester.ac.uk
}

\begin{abstract}
As many IT projects continue to fail, the requirement to implement a project management office (PMO) is simply not an option for large organizations. The current study is an exploratory examination to discover the role of a PMO on IT project failure across the private and public sectors in Saudi Arabia. Data were collected using a survey from 59 IT managers and analyzed using the Statistical Package for the Social Sciences (SPSS). Findings provide empirical evidence on the PMO status in Saudi Arabia. This study finds that there is a difference between organizations that establish a PMO and organizations that do not. In this study, time and cost of IT projects have not been affected by the chosen studied PMO variables (experience, funding, number of staff and location).
\end{abstract}

Keywords: IT project, PMO, Success and Failure

\section{INTRODUCTION}

Today, information technology plays a key role in providing capabilities for almost all sectors to develop their tasks. Many organizations have invested a lot of money in information technology because of increasing awareness that IT investments can be an important source of competitive advantage [25], [28]. For example, the USA spends more than $\$ 250$ billion every year on IT projects [43]. However, most recent studies have demonstrated that the failure rate of IT projects is high. According to CHAOS reports (as cited in [17], [18], [43],[44]), on average over a 16 year period, $29 \%$ are successful, $24 \%$ fail and approximately half (47\%) are challenged projects.

Many studies have covered why IT projects fail. Whittaker indicates three main causes for project failure: poor project planning (specifically, risks were not addressed or the project plan was weak), the business case for the project was weak in several areas or missing several components and a lack of management involvement and support [51].

Normally, a project has two outcomes: success or failure. However, IT project failures include challenged projects. Almost all studies have shown that challenged projects are a type of failed project. Thus, according to CHAOS reports, the average percentage of failed projects during the past 16 years is $71 \%(24 \%+47 \%)$. This is a high rate of failure. Even though challenged projects are not totally failed projects, they are in a grey area. This high rate of project failures causes conflict between project managers on one side and CEOs and stakeholders on the other side.

As numerous IT projects continue to fail, the requirement to establish a PMO will continue. According to Martin et al. "Researchers must further explore the value of a PMO" [27]. This paper is empirical and exploratory in nature and focuses on Saudi Arabia, and it is conducted through questionnaires. It aims to provide a general picture of the establishment of a PMO and its effect on IT projects by exploring the following:

- the difference between the organizations that establish a PMO and organizations that do not

- the variables of a PMO that could affect the time and cost of IT projects

Most organizations have invested huge amount of money in information technology in Saudi Arabia, which has one of the biggest IT markets in the Gulf region [7]. The IT market in Saudi Arabia had a value of US\$3.3 billion in 2010, and is expected to increase to US $\$ 4.6$ billion by 2014 [7]. Also, there will be a huge demand between 2010 and 2014 for software developers, systems analysts, IT project managers and IT consultants [11].

This study extends the previous research performed by Dai [12] and Stewart [44] on the role of a PMO on IT project success. Also, it aims to show IT managers' views about PMOs by answering the following research questions: Do organizations in Saudi Arabia establish a PMO or not? 


\section{Issues in Information Systems}

Volume 14, Issue 1, pp.366-375, 2013

If yes:

Question 1: What is the difference between the organizations that establish a PMO and organizations that do not?

Question 2: What effect do the PMO variables have on IT project's time and cost?

If not:

What are the main obstacles of establishing a PMO in Saudi Arabia?

In order to answer the above research questions, and based on the Research Model in Figure 1, we conducted a survey and analysed the gathered data using the software system of the Statistical Package for Social Science (SPSS).

This paper first gives a brief overview of project management, project success and PMO. Next, it describes the research hypotheses and research model. After that, it describes the research methods and techniques used in the data gathering and analysis. Then, it presents and discusses the results. Finally, the paper summarizes the findings.

\section{Project Management}

\section{LITERATURE REVIEW}

The term project has different definitions, depending on the field of science. The Project Management Institute defines a project as a temporary endeavour undertaken to create a unique product, service or result [35]. Project management is not only a science, but also an art [6]. Activities of planning, implementing, and controlling are concerns of the science of project management, while leadership, team building, and realism are concerns of the art of project management [41].

The Project Management Institute defines project management as the application of knowledge, skills, tools and techniques to project activities to meet the project requirements [35]. Taylor argues that project management is people management [45]. Barnes defines project management as the identification and implementation of beneficial change [3]. Simply, it is how to correctly execute the processing of a project to achieve specific goals.

\section{Project Success and Failure}

The literature has presented many definitions and concepts of success and failure. Standing et al. argue that "project success is equally as complex to define as failure" [42]. It is difficult to know how to measure project success, and the factors of success or failure differ in many studies [33]. Baccarini suggests that project success has two elements: project management success and project product success [2]. De Wit shows that there is a difference between project management success and project success [13]. Avots proposes that project management is a main component of project success [1] which means that project success is achieved through project management. Munns and Bjeirmi show that the overlap between project and project management occurs in: the time frame; the objectives of project success and project management success, which are often intertwined; and ease of measurement [29]. Whilst effective project management may be able to achieve project success, this does not mean, necessarily, that it can prevent project failure [13].

Many researchers have shown that time, cost and user specification are success criteria (e.g., [37], [47], [50]). A successful IT project should meet time, cost and user requirements as well as gauge its effect on IT operations [34]. Time, cost and specification are a small element of the measurements, although they are significant factors for many information technology projects [48]. Wateridge argues that project success can occur, even if it does not meet budget and time schedules [49]. However, a project can be considered as having failed, even if the technical system has achieved its goals [52]. Also, a project can be a success for one party and a failure for another [13].

Finally, it is tricky to define the success or failure of a project because it is a grey area. Wateridge confirms that success and failure are not black and white [48]. Sauer thinks that failure can happen only if there is a developmental or operational termination [39]. Thus, researchers have tried to create or find success factors to lead projects to success.

\section{Project Management Office (PMO)}




\section{Issues in Information Systems \\ Volume 14, Issue 1, pp.366-375, 2013}

The PMO has several other similar names, such as Project Office, Program Office, Project Support Office, Project Control Office, Project Management Group and Project Management Centre of Excellence [36]. According to Parviz, the PMO has become one of the most important topics in current years [32].

Although Dai points out that the use of some sort of PMO goes back to the 1930s [12], this does not reflect the real history of the PMO. According to do Valle et al., publications on the topic of the PMO remained negligible until 2003 [16]. In 1998, Block and Frame pointed to the idea of implementing a project office [4]. Regarding IT projects, organizations began to develop PMOs in the pre-2000 era, in order to manage projects which were involved with Y2K transitions [15].

Even though Desouza and Evaristo claim that "a universal definition of a PMO is not possible" [15], a number of researchers and organizations do provide definitions and it is obviously important to do so. The Project Management Institute (PMI) defines the Project Management Office in the PMBOK Guide as:

"An organizational body or entity assigned various responsibilities related to the centralized and coordinated management of those projects under its domain. The responsibilities of a PMO can range from providing project management support functions to actually being responsible for the direct management of a project." [35].

Some researchers suppose a PMO should only focus on, and support, the tasks of project management within a company. Cappels defines a PMO as: a corporate-level function that provides support, methods, procedures, systems and policy for project management across the company [8]. Some researchers describe a PMO from an organizational, structural viewpoint. For example, Martin et al. define it as a formal, centralized layer of control between senior management and project management [27].

According to Wysocki, a PMO can be either a temporary or permanent unit in organizations [53]. Tinnirello shows that by using a PMO, senior management has a clear path of project management activities [46]. Regarding information technology, Carrillo et al. define a PMO as a key entity for guiding IT projects [9]. Hobbs et al. suggest that the PMO is an organizational innovation [24]. Furthermore, a PMO is a specific unit within the organization, which can have a different and perform different tasks [22].

The roles of the PMO vary significantly, partially based on the levels of the PMO, partially based on the position of staff in the PMO, and partially based on size and objectives of the PMO. Generally, the PMO sets standards and provides methodologies for project management [21]. do Valle et al. conclude with some of the main roles of PMOs, such as development of methodology, reporting, tools, techniques and templates [16]. Roles of the PMO can vary from one company to another, depending on size and objectives [26]. A PMO can implement one or more of the following three roles in a company: consultation, knowledge management and standards setting [15].

\section{Hypotheses Related to Question 1}

\section{RESEARCH HYPOTHESES}

This study has identified variables that could be used to discover the difference between the organizations that establish a PMO and organizations that do not in Saudi Arabia. A pilot study was conducted to identify these potential variables. In this paper, there is one dependent variable: the decision whether or not to establish a PMO and there are 20 independent variables.

To answer Question 1, we have formulated hypotheses for these independent variables as shown in Table 1:

Table 1. Hypotheses related to Question 1

\begin{tabular}{|l|l|}
\hline Null hypothesis H.0 & $\begin{array}{l}\text { There is no significant difference between organizations that establish a PMO and } \\
\text { organizations that do not establish a PMO relative to the independent variable (X) }\end{array}$ \\
\hline Alternative hypothesis H.1 & $\begin{array}{l}\text { There is a significant difference between organizations that establish a PMO and } \\
\text { organizations that do not establish a PMO relative to the independent variable (X) }\end{array}$ \\
\hline
\end{tabular}




\section{Issues in Information Systems \\ Volume 14, Issue 1, pp.366-375, 2013}

\section{Hypotheses Related to Question 2}

Almost all project managers want an IT project that is completed on time within cost. To answer Question 2, this study has also formulated hypotheses for some chosen PMO variables (experience, funding, number of staff and location) that come from a literature review. These variables maybe affecting time and cost of an IT project as shown in Table 2:

Table 2. Hypotheses related to Question 2

\begin{tabular}{|l|l} 
Null hypothesis H.0 & The variable (X) of a PMO has no effect on the time and cost of IT project
\end{tabular}

Alternative hypothesis H.1 $\quad$ The variable (X) of a PMO has an effect on the time and cost of IT project

\section{RESEARCH MODEL}

Few studies (e.g., [12], [44], [23]) have identified variables that influence the implementation of a PMO. This study demonstrates how to apply some of the variables that have been identified by the aforementioned studies. This model is developed based on an extensive literature review and a quantitative survey. The model shows the relationship between the IT project manager, the IT project, and the PMO within an organizational context. The implementation of a PMO cannot be viewed in isolation from the organizational context, nor based solely on the concept of project management; it should be also based on project management practice. To gain a deeper understanding of PMOs, it is necessary to understand the organizational context. The research model for this study is shown in Figure 1.

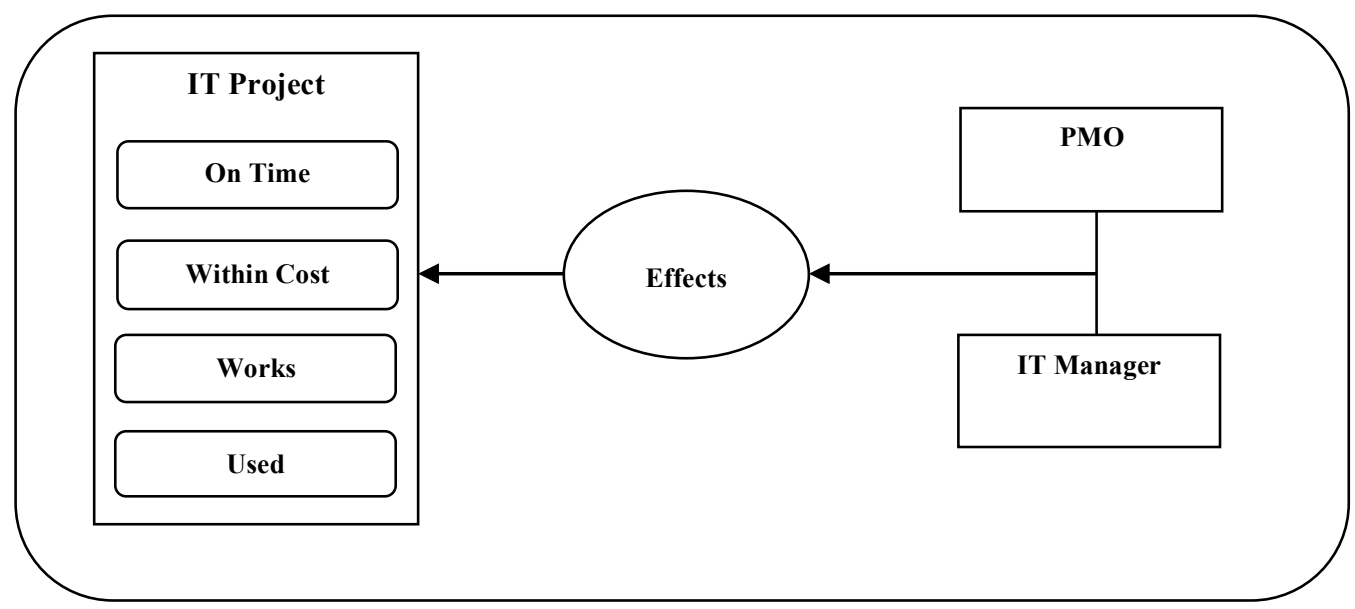

Figure 1. The Research Model

\section{METHODOLOGY}

One of the most common methods of research is a questionnaire. Three studies ([30], [19], [10]) confirm that a survey is still the most common research method in the field of information systems. The study built a questionnaire for IT managers based on an extensive review of the literature and previous studies on the topic of a PMO ([12], [44]). The tool of Google Docs was used to build the questionnaire.

According to the pilot study findings, most respondents did not answer the open questions. Also, it is impossible to classify this type of question. Thus, the study adopted closed-ended questions, including multiple choice, check box and a Likert scale system to ascertain the degree of agreement or disagreement of respondents. A five-point Likert Scale was used, where number 1 means strongly disagree and number 5 means strongly agree. In fact, doing a literature review for this research project helps achieve survey content validity. Conducting a pilot study helps to enhance construct validity by helping to understand the survey questions.

It is important to be aware that studies vary on their opinion of the optimum sample size. Saunders et al claim that a sample size of 30 is sufficient to conduct statistical analysis [40], while Hair et al demonstrate that 100 is the 


\section{Issues in Information Systems \\ Volume 14, Issue 1, pp.366-375, 2013}

minimum [20]. Furthermore, samples from 30 to 500 are proper for most research [38]. According to Yu and Cooper, it is extremely undesirable if the response rates are under $20 \%$ [54].

The target population of this particular study project is the IT managers in Saudi Arabia to whom the survey applies. The study applied non-probability sampling represented in purposive sampling and snowball sampling techniques to gather data among IT managers. It is impossible to reach every IT manager in the target population in Saudi Arabia. Questionnaires were sent to the two groups (173 participants) by post and email, one to IT managers in the private sector and the other one to IT managers in the public sector. The sample frame was distributed across five geographical areas in Saudi Arabia (Dhahran, Riyadh, Jeddah, Yanbu and Madinah) as follows: 100 participants in the private sector and 73 participants in the public sector. The attachments in the postal survey were the questionnaire, cover letter and response envelope. To test the validity of the email addresses and to guarantee high response rates, prior to sending the questionnaire the researcher sent every IT manager an email.

In response to the email, 71 IT managers out of 100 in the private sector replied, welcoming the opportunity to participate, and 53 IT managers out of 73 from the public sector responded similarly. Thus, the questionnaires were sent in two versions (English and Arabic) by email to 124 participants and by post to 49 participants in the middle and end of July 2012.

Two emails and one letter were sent to all who had not initially completed the questionnaire, to increase the response rate. By the middle of September 2012, 69 questionnaires were returned to the researcher. 37 questionnaires ( 28 by email and 9 by post) out of 100 were returned by IT managers in the private sector, and 32 questionnaires ( 19 by email and 13 by post) out of 73 were returned by IT managers in the public sector. Only $5.78 \%$ of the sample was excluded due to missing data by eliminating ten questionnaires (four from the private and six from the public sector). The remaining 59 questionnaires (33 from private and 26 from public) were coded and analyzed using SPSS. The response rate of sample size was $34.1 \%$ which was considered sufficient for analysis [14].

\section{DATA ANALYSIS AND RESULTS}

The valid data from IT managers in Saudi Arabia were analyzed using the software system of the Statistical Package for Social Science (SPSS). Descriptive statistics are frequently used in the initial part of a statistical analysis through tables, graphs and measures [5]. They are used to gain more understanding of the research project data.

\section{Descriptive Statistics}

$66.1 \%$ of the IT managers were Saudi and $33.9 \%$ were non-Saudi. The initial reading of these figures indicates that the IT industry in Saudi Arabia still depends on foreign expatriates, especially as experts. $88.1 \%$ of the respondents were male while $11.9 \%$ were female. It is clear that there is an IT gender gap in Saudi Arabia. $81.3 \%$ were between 30 and 45 years. It is supposed that IT projects were most likely to be managed by managers in this age group. The majority of respondents had a Bachelor degree $(76.3 \%)$. From the five options (extremely good, very good, good, not very good, and not at all), $78 \%$ of respondents claimed that their English language skills were 'good'. It is clear that English is the language of technology, especially the science of information systems. More than half of respondents had a background in IT and computing (54.2\%). 44.1\% of IT managers had experience of between three and six years in the IT industry.

\section{Establishing a PMO in Saudi Arabia}

The primary research question is: Do organizations in Saudi Arabia establish a PMO or not?

This study finds that $76.3 \%$ of the respondents had not implemented a PMO while $23.7 \%$ had established a PMO in their organizations. The reason for this may be that a PMO is a new concept in the IT industry in Saudi Arabia. Furthermore, $50 \%$ of the respondents had a temporary PMO, and 50\% had a permanent PMO in their organizations. 


\section{Issues in Information Systems}

Volume 14, Issue 1, pp.366-375, 2013

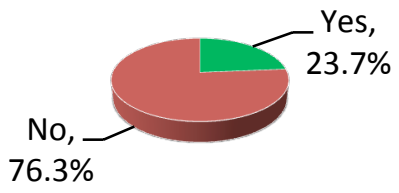

Figure 2. The Establishment of PMO

For organizations that established a PMO, the majority of respondents indicated that the PMO reported to top management and only $7.1 \%$ indicated that the PMO reported to middle management; all the respondents believed that the top management supports the PMO unit in organizations; $78.6 \%$ of the respondents claimed that the total number of PMO members was between 8 and 11 employees. 21.4\% claimed it was between 3 and 7 employees; $71.4 \%$ of the respondents felt that the PMO members did not have PMP certification and only $28.6 \%$ felt that they had PMP certification. The frequency distribution of average experience of PMO staff is as follows: $64.3 \%$ of the respondents reported that the average experience of PMO staff was between 11 and 15 years. $21.4 \%$ reported it was between 16 and 20 years while $14.3 \%$ reported that it was between 5 and 10 years. Regarding the location of the PMO, $64.3 \%$ of the respondents indicated that PMO was directly under the CEO. 28.6\% indicated that it was directly under the CEO but at the same level with other departments such as IT, Human Resource, accounting, etc. Only $7.1 \%$ claimed that it was directly under the CEO with the IT department under the PMO.

For organizations that established a PMO, $42.9 \%$ of the respondents reported that the PMO can reduce the number of challenged IT projects. $28.6 \%$ reported that the PMO can increase the number of successful IT projects while $21.4 \%$ felt that the PMO can decrease IT risks. Only $7.1 \%$ felt that the PMO can decrease the number of failed IT projects.

\section{Differentiating between the Organizations that Establish a PMO and Organizations that do not}

This section will discover the difference between the organizations that establish a PMO and organizations that do not. This paper will discuss 20 independent variables derived from the literature for three groups as shown in Table 3.

The Pearson chi-square tests were employed in the data analysis to examine hypotheses. In this study, the null hypothesis is that there is no statistically significant difference between the organizations that establish a PMO and those that do not in Saudi Arabia. In testing a hypothesis, nominal data can be structured in a two-by-two data matrix that consists of two rows and two columns. The null hypothesis can be accepted or rejected based on the result of the chi-square test. To accept the null hypothesis and reject the alternative hypothesis, the significance level of chi-square should be more than .05 [31].

Table 3. Variables and Chi-Square Tests

\begin{tabular}{|l|l|c|c|c|}
\hline Group & Variables & P-value & Level of sig. & Decision \\
\hline IT manager & Nationality & .075 & .05 & Accepted \\
\hline & Gender & 1.000 & .05 & Accepted \\
\hline & Age & .358 & .05 & Accepted \\
\hline & Educational level & .644 & .05 & Accepted \\
\hline & English language skills & $\mathbf{. 0 1 6}$ & .05 & Rejected \\
\hline & Study field & .688 & .05 & Accepted \\
\hline & IT experience & .170 & .05 & Accepted \\
\hline Organization & Industry area & $\mathbf{. 0 0 1}$ & .05 & Rejected \\
\hline & Number of employees & $\mathbf{. 0 0 0}$ & .05 & Rejected \\
\hline & Number of IT employees & $\mathbf{. 0 0 2}$ & .05 & Rejected \\
\hline IT project & size of IT project & $\mathbf{. 0 0 0}$ & .05 & Rejected \\
\hline & IT project team size & $\mathbf{. 0 2 7}$ & .05 & Rejected \\
\hline & Intended client & .428 & .05 & Accepted \\
\hline & Intended supplier & $\mathbf{. 0 1 4}$ & .05 & Rejected \\
\hline
\end{tabular}




\section{Issues in Information Systems}

Volume 14, Issue 1, pp.366-375, 2013

\begin{tabular}{|l|l|l|l|l|}
\hline & Completed on time & .193 & .05 & Accepted \\
\hline & Completed within cost & .131 & .05 & Accepted \\
\hline & Work & .618 & .05 & Accepted \\
\hline & Used & .303 & .05 & Accepted \\
\hline & IT project outcome & .490 & .05 & Accepted \\
\hline & Using PM methodology & $\mathbf{. 0 2 9}$ & .05 & Rejected \\
\hline
\end{tabular}

In this analysis, out of the 20 independent variables studied and associated with the dependent variable, only eight had a significance level smaller than or equal to .50 , which were English language skills, industry area, number of employees, number of IT employees, size of IT project, IT project team size, intended supplier of IT project and using project management methodology as shown in Table 3.

In the case of Saudi Arabia, a PMO is more likely to be established where the IT manager had good English language skills. Private and larger organizations are more likely to establish a PMO. Furthermore, a PMO is more likely to be implemented for organizations that decided to outsource their IT operations and which used project management methodology.

\section{Can PMO Variables Affect Time and Cost of an IT Project?}

The goal of this section is to explore PMO variables that can affect time and cost of an IT project using one-way ANOVA tests. A one-way ANOVA is used to examine the variance between means of PMO variables in response to the criteria of an IT project. These criteria are:

- IT project is completed on time

- IT project is completed within cost

The analysis explores the significant relationship between four selected independent PMO variables and the dependent variables of time and cost of IT projects in Saudi organizations. When there is a significant effect between a variable factor of a PMO and the time and cost of IT project, relationship is considered. There is a significant effect if the value of ANOVA is less than .05 [31]. The following shows the findings of ANOVA test by assuming two kinds of hypotheses: null and alternative as previously mentioned in the earlier Research Hypotheses section.

Table 5. A One-Way ANOVA Tests

\begin{tabular}{|l|c|c|c|c|}
\hline \multirow{2}{*}{ PMO Variables } & \multicolumn{2}{|c|}{ F } & \multicolumn{2}{c|}{ Sig. } \\
\cline { 2 - 5 } & Time & Cost & Time & Cost \\
\hline Experience of PMO Staff & .534 & .246 & .601 & .786 \\
\hline Funding level for PMO & .015 & .536 & .904 & .478 \\
\hline Number of PMO Members & .405 & .257 & .537 & .621 \\
\hline PMO location & .107 & .246 & .899 & .786 \\
\hline
\end{tabular}

As shown in Table 5 above, no statistically significant differences were discovered in the analysis. Thus, this study finds that there is no PMO variable that statistically affects the time and cost of an IT project, although $42.9 \%$ of the sample in organizations that established a PMO claimed that it can reduce the number of challenged IT projects.

\section{Obstacles to Establishing a PMO in Saudi Arabia}

For organizations that did not establish a PMO in this study in Saudi Arabia, $62.2 \%$ of the respondents claimed that their organizations intend to establish a PMO while $37.8 \%$ reported that their organizations do not intend to implement a PMO. For organizations that intended to establish a PMO, only $3.6 \%$ indicated that his/her organization intends to establish a PMO within 6 months. 25\% felt that their organizations aim to implement a PMO within 12 months while $42.9 \%$ of the respondents claimed that their organizations intend to set up a PMO within 18 months. $28.6 \%$ indicated that their organizations plan to establish a PMO within 24 months. This paper finds that lack of understanding of a PMO's value and roles is the obstacle that had a high overall agreement of respondents. 


\section{Issues in Information Systems \\ Volume 14, Issue 1, pp.366-375, 2013}

\section{DISCUSSION}

According to this study, there are three significant contributions to the literature as follows: The first contribution is providing empirical evidence on the status of a project management office in the public and private sectors in Saudi Arabia. According to the researchers' knowledge, this paper is a first attempt to empirically discover the status of a PMO. As reflected from the descriptive statistics, Saudi organizations still depend on foreign expatriates in IT projects. Saudi Arabia, like many countries, has an IT gender gap. This study finds that establishing PMOs is at a minimum level in the state of a rich country such as Saudi Arabia.

The second contribution is that there is a difference between organizations that establish a PMO and organizations that do not in Saudi Arabia. In this study, an IT manager who has mastered the English language will be more capable to understand and establish a PMO. Also, PMOs are more likely to be established for larger and private organizations rather than smaller and public organizations. Our findings suggest that the size of an IT project is one critical factor for organizations that established a PMO. Larger IT projects probably make organizations seek to establish PMOs. It is derived from this study that PMOs are more likely to be established for private and bigger organizations that have the ability to outsource their IT functions for third party supplier. There is a significant difference between organizations that establish a PMO and organizations that do not establish a PMO relative to using project management methodology. One possible explanation for this difference is that many methodologies refer to information about the concept of PMO.

The third contribution of this paper is that the studied PMO variables have no evident effect on time and cost of an IT project especially PMO staff experience, size and location. A future study investigating the role of PMO on quality of IT projects would be very interesting.

\section{CONCLUSIONS}

The current study was designed to determine the effect of a PMO on IT projects in Saudi Arabia. Returning to the questions and hypotheses posed in this study, there is now potential to state that there is probably a misunderstanding of a PMO's value and roles for organizations that did not establish a PMO and maybe not appreciating all the potential benefits of a PMO for organizations that established a PMO. Further research regarding understanding the role of PMO would be of great help in knowing where stakeholders such as IT managers, senior managers and project management officers stand. It is important to note that establishing a PMO is maybe in an immature stage for Saudi organizations because it is a new concept. In this case, a PMO has a little influence on IT projects.

This study has some limitations. First, the sample population used in this study may not represent all IT managers in Saudi Arabia because of limitations of time and cost. It is difficult to reach every IT manager in the target population so non-probability sampling was applied. Therefore, findings of this study should only be generalized with great caution due to the small sample size. Second, the questionnaire employed close-ended questions which may limit the participants' selections to completely explain response choices. Although this study is not perfect, it provides a solid entry point for researchers to do further study on a PMO and for project management companies to introduce their services and trainings in Saudi Arabia.

\section{REFERENCES}

1. Avots, I. (1969). Why does project management fail? California management review, 12, 77-82. [1]

2. Baccarni, D. (1999). The logical framework method for defining project success. Project Management Journal, 30(4), 25-32. [2]

3. Barnes, Martin. (1990). Innovation - Why project management is essential to successful businesses. Handbook of Management by Projects. Roland GareisVienna: Manz. [3]

4. Block, T.R, and Frame, J.D. (1998). The project office. Menlo Park, CA: Crisp Learning. [4]

5. Bryman, A. and Cramer, D. (1996). Quantitative data analysis with minitab. A Guide for social Scientists. London, Routledge.

6. Burbridge, R.N. (1989). Conception of projects. International Journal of Project Management, 7 (2), 117-119.

7. Business Monitor International Ltd. (2010). Saudi Arabia: Information Technology Report. London:BMI. 


\section{Issues in Information Systems}

Volume 14, Issue 1, pp.366-375, 2013

8. Cappels, T. M. (2004). Financially focused project management. Boca Raton, FL : J. Ross Pub.

9. Carrillo, J. V., Abad, M.E., Cabrera, A. S. and Jaramillo, D.H. (2010). Success factors for creating a PMO aligned with the objectives and organizational strategy. Andescon, 2010 IEEE.

10. Chen, W. S., and Hirschheim, R. (2004). A paradigmatic and methodological examination of information systems research from 1991 to 2001. Information Systems Journal, 14(3), 197-235.

11. Communications and Information Technology Commission. (2009). Kingdom of Saudi Arabia: IT Report. Riyadh:CITC.

12. Dai, X.C. (2001). The role of the project management office in achieving project success. W. G. Wells, Jr. United States, District of Columbia, The George Washington University.

13. De Wit, A. (1988). Measurement of project success. International Journal of Project Management, 6(3): 164170.

14. Denscombe, M. (1998). The Good Research Guide: For Small-scale Social Research Projects. Buckingham: Open University Press.

15. Desouza, K.C. and Evaristo, J.R. (2006). Project management offices: A case of knowledge-based archetypes. International Journal of Information Management, 26(5): 414-423.

16. do Valle, J.,Angelo Santos, da Silviera, E. S., and Soares, C. A. P. (2008). Project management office (PMO): principles in practice. AACE International Transactions, PM71-PM79.

17. EPL 603 Topics In Software Engineering. (2012). Retrieved February 6, 2013, from Department of Computer Science, University of Cyprus. Website: http://www.cs.ucy.ac.cy/ cs00pe/ep1603/labs/Lab08.pdf

18. Eveleens, J. and Verhoef, C. (2009). The rise and fall of the Chaos report figures, IEEE Software. Available via www.cs.vu.nl/ $\sim$ x/chaos/chaos.pdf.

19. Farhoomand, A.F. and Drury, D.H. (1999). A Historiographical examination of Information Systems. Communications of the Association for Information Systems, 1, 1-27.

20. Hair, J. et al. (1992). Multivariate Data Analysis. New York, Macmillan.

21. Hardy, L. and Chaudhuri T. (2001). Designing an effective project management office. In: Tinnirello PC (ed) New directions in project management. Auerbach Publications, Philadelphia, pp 447-460.

22. Hill, G. M. (2008). The complete project management office handbook. $2^{\text {nd }}$ ed. Published: Boca Raton : Auerbach.

23. Hobbs, B. and Aubrey, M. (2010). The Project Management Office: A Quest for Understanding. PM Network. United States, Drexel Hill, Project Management Institute. 24: 69-69.

24. Hobbs, B. et al (2008). The project management office as an organisational innovation. International Journal of Project Management, 26(5): 547-555.

25. Imamoglu, O. and Gozlu, S. (2008). The sources of success and failure of information technology projects: Project managers' perspective. PICMET.

26. Kwak, Y.H. and Dai, C.X. (2000). Assessing The Value Of Projectmanagement Offices (PMO). PMI Research Conference.

27. Martin, N.L., Pearson, J.M. and Furumo, K. (2007). IS project management: size, practices, and the project management office. The Journal of Computer Information Systems, 47(4), 52-60.

28. McAfee, A. and Brynjolfsson, E. (2008). Investing in the IT That Makes a Competitive Difference. Harvard Business Review, July-August: $98-107$.

29. Munns, A.K. and Bjeirmi B.F. (1996). The role of project management in achieving project success. International Journal of Project Management, 14(2): 81-87.

30. Orlikowski, W.J. and Baroudi, J.J (1991). Studying Information Technology in Organizations: Research Approaches and Assumptions. Information Systems Research, 2(1):1-8.

31. Pallet, J. (2010). SPSS survival manual: A step by step guide to data analysis using SPSS for Windows. Crows Nest.

32. Parviz, F.R. (2000). Implementing a PMO. Project Management Journal, 31(4).

33. Pinto, J.K. and Slevin, D.P. (1988). Critical Success Factors Across the Project life Cycle. Project Management Journal, pp 67-75.

34. Powers, R.F. and Dickson, G.W. (1973). MIS Project Management: Myths, Opinions and Realities, California Management Review, 15, 3, $147-156$.

35. Project Management Institute. (2008). A Guide to the Project Management Body of Knowledge (PMBOK® Guide), Third edition, USA.

36. Rad, P.F. and Levin, G. (2002). The Advanced Project Management Office: A Comprehensive Look at Function and Implementation. CRC Press, Boca Raton, FL. 


\section{Issues in Information Systems}

Volume 14, Issue 1, pp.366-375, 2013

37. Rook, P. (1986). Controlling software development projects, Software Engineering Journal, Vol 1, No 1, pp 7 16.

38. Roscoe, J. (1975). Fundamental research statistics for the behavioural sciences. New York, Holt, Rinehart and Winston.

39. Sauer, C. (1988). The value of case studies in understanding organisational aspects of information systems. Internal paper, Department of Computer Science, University of Western Australia.

40. Saunders, M., Lewis, P. and Thornhill, A. (2003). Research Methods for Business Students, 3rd edition, Financial Times Prentice Hall, Harlow.

41. Soldano, D. and Krueger, L. (1994). Introduction to project management. Northcon/94 Conference Record.

42. Standing, C., Guilfoyle, A., Lin, C. and Love, P., 2006. The attribution of success and failure in IT projects. Industrial Management \& Data Systems, 106(8).

43. Standish Group. (1994). Chaos Report. Boston, MA.

44. Stewart, J.S. (2010). The role of the Project Management Office on Information Technology project success. W. Gottwald. United States, Minnesota, School of Business.

45. Taylor, H.N. (1989). Project Management is People Management!, Project Management Institute Seminar/Symposium, Atlanta, Georgia - October 7 - 11, 1989, pp 256 - 263.

46. Tinnirello, P. C. (2002). New directions in project management. Published: Boca Raton : Auerbach.

47. Wallace, D. (1990). Get it done! - Project management your most valuable tool. Success, Vol 37, pp 46 - 47.

48. Wateridge, J. (1997). Training for IS/IT project managers: A way forward. International Journal of Project Management, 15(5): 283-288.

49. Wateridge, J. (1998). How can IS/IT projects be measured for success? International Journal of Project Management,16(1): 59-63.

50. Weitz, L. (1989). How to implement projects properly. Software magazine, Vol 9, No 13, pp $60-69$.

51. Whittaker, B. (1999). What went wrong? Unsuccessful information technology projects. Information Management \& Computer Security, 7(1): 23-29.

52. Wilson, M. and Howcroft ,D. (2002). Re-conceptualising failure: social shaping meets IS research. European Journal of Information Systems, 11: 236-250.

53. Wysocki, R.K. (2009). Effective project management: traditional, agile, extreme. 5th ed, New York: Wiley.

54. Yu, J. and Cooper, H. (1983). A qualitative review of research design effects on response rates to questionnaires. Journal of Marketing Research, vol. 36, pp. 36-44. 